\title{
Effect of Eggshell on Mechanical Properties of Epichlorohydrin Cross-linked Chitosan/Eggshell Composites
}

\author{
RAHMI*, MARLINA and NISFAYATI \\ Chemistry Department, Syiah Kuala University, Banda Aceh 23111, Indonesia. \\ *Corresponding author E-mail: rahmi@ fmipa.unsyiah.ac.id
}

http://dx.doi.org/10.13005/ojc/330156

(Received: September 19, 2016; Accepted: January 29, 2017)

\begin{abstract}
The effect of eggshell particles on the mechanical properties of epichlorohydrin crosslinked chitosan/eggshell composites had been studied. The content of eggshell particles in each composites was varied from 2.5 to $13.4 \%(\mathrm{w} / \mathrm{w})$. The tensile strength was $60 \%$ improved, compared to the control chitosan. The composite with $13.4 \%(\mathrm{w} / \mathrm{w})$ content of eggshell particles showed the optimum tensile strength. The XRD patterns exhibited the decrease in peak intensity of chitosan at $2 \theta=20^{\circ}$ due to the addition of epichlorohydrin as a crosslinking agent of chitosan and incorporation of eggshell particles to crosslinked chitosan. The peak intensity at $2 \theta=44^{\circ}$ was increased due to the addition of eggshell particles. Scanning elecron microscopy images confirmed the eggshell particles was dispersed into chitosan matrix.
\end{abstract}

Keywords: Eggshell, Chitosan, Epichlorohydrin, Composite.

\section{INTRODUCTION}

Biopolymers have received much attention in many applications due to their environmental friendly ${ }^{1-3}$. However, the development of biopolymers with performance an equals to common synthetics polymers is still an open challenge. Chitosanbased materials seem to be an attractive source for development of biodegradable polymers. Chitosan can be considered as a good replacement for synthetic polymers due to its biodegradability, availability, non-toxicity, and low cost materials.
Chitosan is a partially deacetylated derivative of chitin. Chitin can be found in fungal species, insects and crustaceous shells. The most abundant natural polysaccharide after cellulose is chitosan ${ }^{4}$. Chitosan is a beta 1.4 linked linear biopolymer that contains $80 \%$ poly(D-glucosamine) and $20 \%$ poly(N-acetyl-D-glucosamine $)^{5}$. The high content of amino and hydroxyl groups in chitosan favors its biopolymer modification. Native chitosan itself has poor mechanical properties and soluble in most dilute organic acids, such as formic and acetic acids. In order to improve its properties, 
various methods had been developed to enhance the chitosan positive characteristics, such as by using crosslinking agents or adding fillers. The treatment using crosslinking agents creates highly dissolution resistance of polymer due to the formation of new linkages between the chitosan chains. The crosslinking procedures can be conducted by reacting chitosan with different crosslinking agents such as polyethylene glycol diglycidyl, ethylene glycol diglycidyl ether, glutaraldehyde and epichlorohydrin $^{6-10}$.

Another method to improve the polymer properties is filler addition. Hassan, S. B. and V. S. Aigbodion (2015) had used eggshell as a filler in the reinforcement of metal-matrix composites ${ }^{11}$. Eggshell is one of by-products from food industries and restaurants which is daily produced in a huge amount. The huge amount of eggshell will cause environmental pollution. The utilization of eggshell for composite preparation will increase the added value of eggshell and reduce the environmental pollution. Eggshell contains $94 \%$ of calcium carbonate, $1 \%$ of calcium phosphate, $1 \%$ of magnesium carbonate and $4 \%$ of organic matter. The use of eggshell as a filler to improve mechanical properties of polymers has some advantages, such as readily available, low cost, and naturally renewable. The chemical composition and availability of eggshell make it become a potential source of filler for the composite polymers.

Therefore, the purpose of this study is the improvement of mechanical properties of chitosan polymer by the addition of eggshell particles to the chitosan that had been crosslinked by epichlorohydrin, to result in a biodegradable, renewable and low cost material for the replacement of synthetic polymers. In this study, composites were prepared by various eggshell contents. The characterization of composites was done by using tensile test, FTIR, SEM and XRD.

\section{MATERIALS AND METHODS}

Eggshell was collected from some restaurants in Banda Aceh, Indonesia. Chitosan (deacetylation value: 75.0 to $85.0 \%$ ) and epichlorohydrin were supplied by Tokyo Chemical Industry Co., Ltd. Japan and used as received.

\section{Preparation of eggshell particles}

Collected eggshell was cleaned by washing it with hot distilled water. The membranes of eggshell were removed. The cleaned eggshell was dried at $50^{\circ} \mathrm{C}$ for $5 \mathrm{~h}$ and grounded into powder using ball milling machine at $250 \mathrm{rpm}$

\section{Preparation of Epichlorohydrin Crosslinked Chitosan/Eggshell Composites}

The epichlorohydrin crosslinked chitosan/ eggshell composite was prepared by phase inversion method. Chitosan ( $1 \mathrm{~g}$ ) was dissolved by adding it to a $250 \mathrm{~mL}$ beaker containing $100 \mathrm{~mL}$ of acetic acid solution (2\%). In order to complete dissolvation, the mixture was magnetically stirred at $500 \mathrm{rpm}$ for $3 \mathrm{~h}$. An aliquot of $0.8 \mathrm{~mL}$ epichlorohydrin was added to the chitosan solution and magnetically stirred at 500 rpm for $1 \mathrm{~h}$. Then eggshell particles were added to the viscous solution and homogenized for $3 \mathrm{~h}$. Chitosan film was then cast by applying the epichlorohydrin crosslinked chitosan/eggshell suspension onto petri dish and dried for $24 \mathrm{~h}$ at room temperature. Dried composite film was peeled off from petri dish and then stored.

\section{RESULTS AND DISCUSSION}

\section{Mechanical properties of the epichlorohydrin crosslinked chitosan/eggshell composites}

The tensile strength of epichlorohydrin crosslinked chitosan/eggshell composite was observed as a function of the eggshell addition ranging between 2.5 to $13.4 \%$ (w/w) (Fig. 1). The tensile strength of pure chitosan was found to be $12.30 \mathrm{kgf} / \mathrm{mm}^{2}$ and the composites with addition 2.5; 9.3 and $13.4 \%(\mathrm{w} / \mathrm{w})$ eggshell particles increased the tensile strength up to $13.90 ; 16.80$ and $19.70 \mathrm{kgf} / \mathrm{mm}^{2}$ respectively. The addition $13.4 \%(\mathrm{w} / \mathrm{w})$ of eggshell improved the tensile strength $60 \%$ compared to pure chitosan.

The tensile strength values of the epichlorohydrin crosslinked chitosan/eggshell composites increased due to the favorable fillermatrix interactions. The filler-matrix interaction was the interaction between the anionic carbonate groups of eggshell (filler) and the cationic amine groups of chitosan (matrix). This interaction might favor a good interface between the matrix and filler and lead to high tensile strenght values of the composites. 
Effective stress transfer at the interface of the fillermatrix also induced the reinforcing of composites.

\section{Fourier Transform Infrared Spectroscopy}

Fig. 4 demonstrates the FTIR spectra of chitosan, eggshell and crosslinked chitosan/eggshell composite. As seen in Fig. 2(a) the characteristic absorption bands of the streching of $-\mathrm{OH}$ and $-\mathrm{CH}_{2} \mathrm{OH}$ vibrations of chitosan appeared at 3250$3500 \mathrm{~cm}^{-1}$, overlapped with streching $-\mathrm{NH}_{2}$ (3400$3500 \mathrm{~cm}^{-1}$ ) and $-\mathrm{NH}$ secondary amides vibrations $\left(3280-3300 \mathrm{~cm}^{-1}\right)$. The absorption bands at $2925 \mathrm{~cm}^{-1}$ and $2855 \mathrm{~cm}^{-1}$ showed the $\mathrm{C}-\mathrm{H}$ streching vibration of the polymer backbone. The absorption bands at $1084 \mathrm{~cm}^{-1}$ was related to the stretch vibrations of C-O. The absorption bands appeared at 1633 $\mathrm{cm}^{-1}$ and $1589 \mathrm{~cm}^{-1}$ related to amide I and amide II vibrational mode, respectively. Primary alcoholic group in chitosan was assigned at absorption band of $1399 \mathrm{~cm}^{-1}$.

Fig. 2(b) showed the typical absorption bands of calcite $\left(\mathrm{CaCO}_{3}\right)$ as main component of eggshell at 1405, 871 and $713 \mathrm{~cm}^{-1}$. Asymmetric streching vibration of carbonate moiety appeared at absorption band of $1405 \mathrm{~cm}^{-1}$. The absorption band at $871 \mathrm{~cm}^{-1}$ was related to in-plane bending vibrations of carbonate moiety and the absorption band at 713 $\mathrm{cm}^{-1}$ was related to out-of-plane bending vibrations

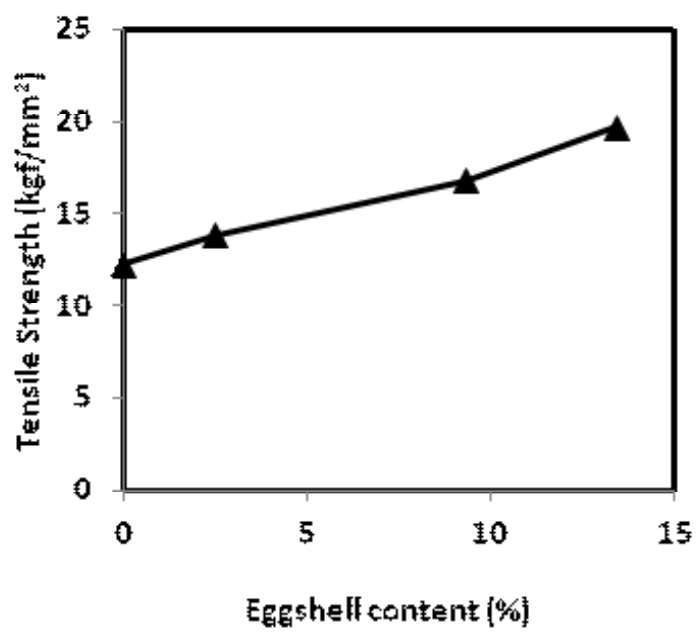

Fig. 1: The tensile strength of composites as a function of eggshell content of carbonate moiety. These spectra are in agreement with those obtained by different authors ${ }^{12-13}$. The occurence of corresponding absorption bands for eggshell (1405, 871 and $\left.713 \mathrm{~cm}^{-1}\right)$, epichlorohydrin and chitosan in the FTIR spectrum of epichlorohydrin crosslinked chitosan/eggshell composite (Fig. 2c.) confirmed their combination within composite.

\section{Scanning Electron Microscopy (SEM)}

SEM was used for the characterization of materials from the initial one to the composite. Scanning electron micrographs of chitosan chitosan, eggshell particles and epichlorohydrin crosslinked chitosan/eggshell were shown in Fig. 3. Scanning electron micrographs of chitosan (Fig. 3(a) and (b)) appeared as non-particulate and smooth structure. After crosslinking and addition of eggshell particles (Fig. 3(e) and (f)), the surface exhibits a large number of flower-like particles. Scanning electron micrographs of eggshell particles (Fig. 3(c) and (d)) exhibited particle size range of $5-10 \mathrm{~mm}$. Scanning electron micrographs of epichlorohydrin crosslinked
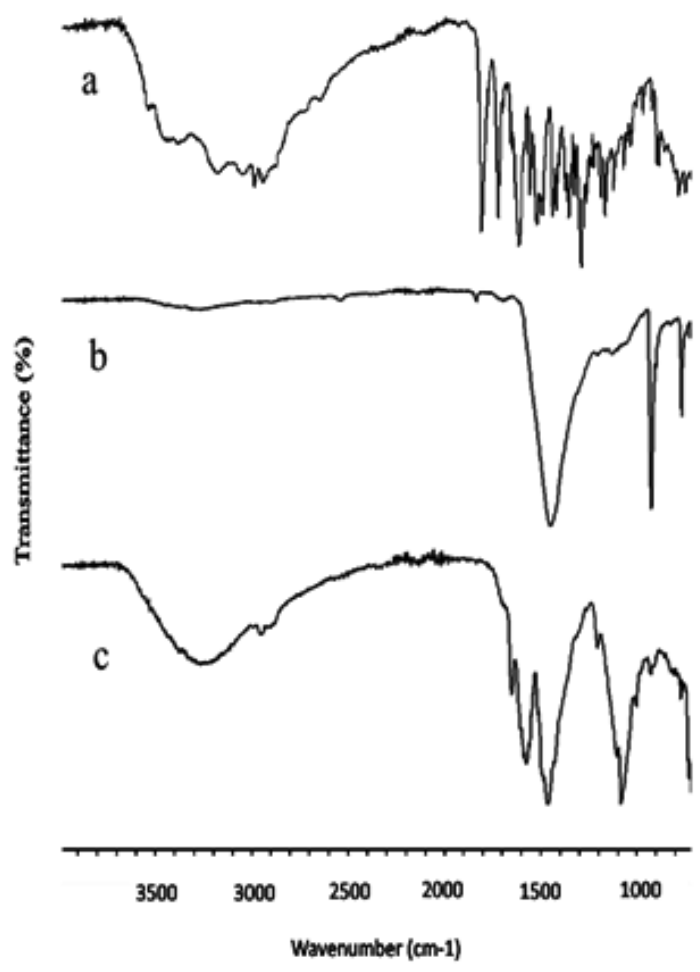

Fig. 2: FTIR spectra of (a) chitosan (b) eggshell and (c) epichlorohydrin crosslinked chitosan-eggshell composite 
chitosan/eggshell showed eggshell particles distributed on the surface of chitosan matrix .

\section{X-Ray Diffraction (XRD)}

XRD characterization was used for structural analysis of eggshell, chitosan and epichlorohydrin crosslinked chitosan/eggshell composite. Fig. 4 showed the diffractograms of eggshell, chitosan, and epichlorohydrin crosslinked chitosan/eggshell composite.

Diffractogram of eggshell exhibited characteristic peak of calcite $\left(\mathrm{CaCO}_{3}\right)$ at $2 \theta=28^{\circ}$ (Fig. 4(a)). The diffractogram of chitosan exhibited crystalline peak at $2 \theta=20^{\circ}$ as shown in Fig. $4($ b). Paulino, et. al. (2008) also reported that the characteristic peak for chitosan was in range of 2-Theta=20-2314. Due to the formation of crosslinked chitosan and incorporation of eggshell to crosslinked chitosan, a decrease in peak intensity at $2 \theta=20$
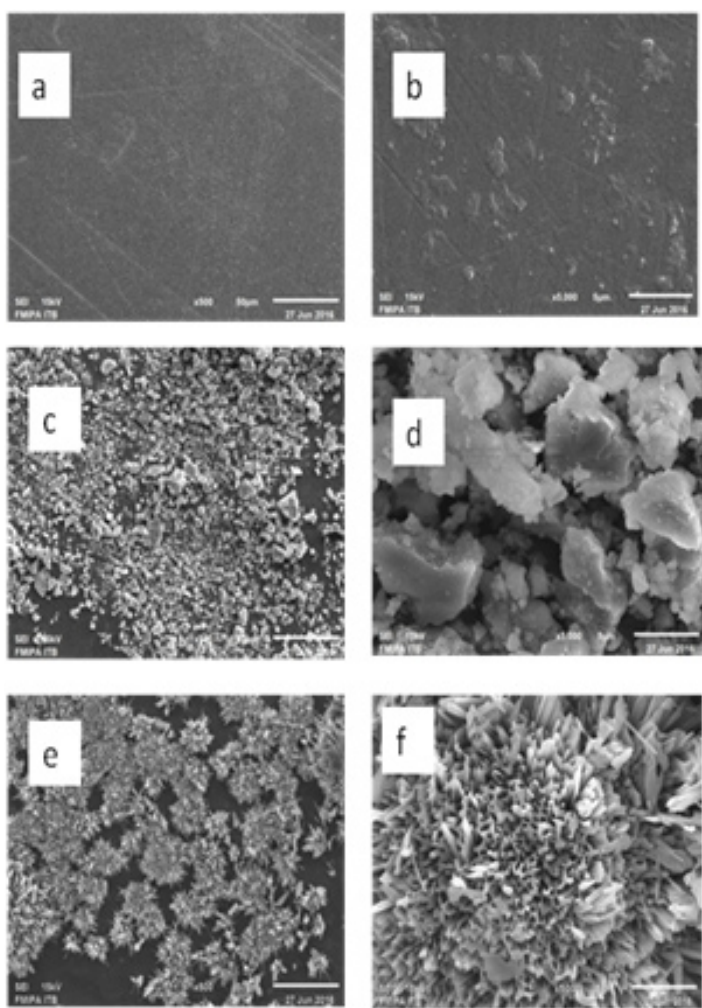

Fig. 3: Scanning electron micrographs of chitosan $(a, b)$, eggshell particles (c,d), and epichlorohydrin crosslinked chitosan/eggshell composite $(e, f)$ was observed in diffractogram of epichlorohydrin crosslinked chitosan/eggshell composite (Fig. $4(c))$. The degree of crystallinity of composite was considerably lower than native chitosan because chitosan crystals were destroyed in the processing.

The peak of calcite after treatment with chitosan and epichlorohydrin at $29^{\circ}$ disappeared and high intensity peak appeared at $44^{\circ}$, indicating that phase transition of $\mathrm{CaCO}_{3}$ from calcite to vaterite structure (Fig. 4(c)). The chemical composition of vaterite is the same as calcite. But in terms of symmetry, they have different crystal structure, orientation of $\mathrm{CO}_{3}$ ions, and coordination environment of $\mathrm{Ca}$ ions ${ }^{15}$

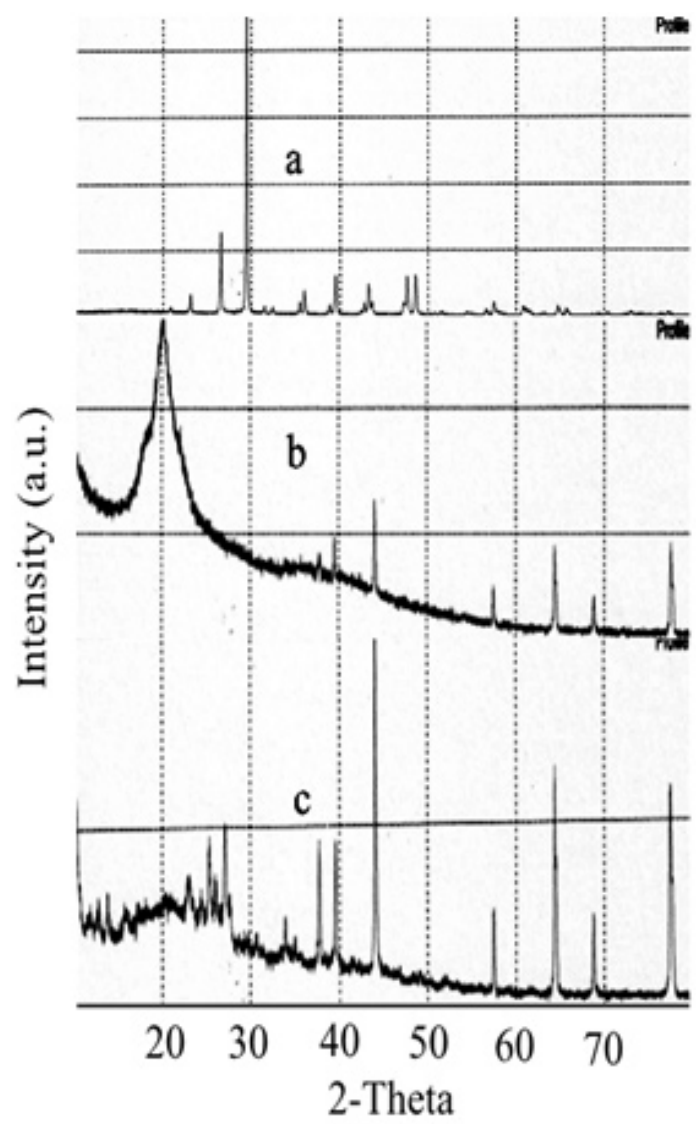

Fig. 4: XRD patterns of (a) eggshell (b) chitosan and (c) epichlorohydrin crosslinked chitosaneggshell composite 


\section{CONCLUSIONS}

It was observed that eggshell particles succesfully incorporated in epichlorohydrin crosslinked chitosan. The microstructure analysis shows the distribution of eggshell particles in the epichlorohydrin crosslinked chitosan matrix. The distribution of eggshell particles in the microstructure of the composites is the major factor responsible for the improvement of tensile strength of the composites. Incorporation of eggshell particles in crosslinked chitosan can lead to the production of low cost polymer composites.

\section{ACKNOWLEDGEMENTS}

The financial support of the Directorate General of Higher Education, Indonesia (DIKTI), is acknowledged.

\section{REFERENCES}

1. Sell, S. A.; Wolfe, P. S.; Garg, K.; McCool, J. M.; Rodriquez, I. A.; Bowlin, G. L. Polym. 2010, 2, 522-553.

2. Goff, K. J. L.; Gaillard, C.; Helbert, W.; Garnier, C.; Aubry, T. Carbohydr. Polym. 2015, 116, 117-123.

3. Rahmi; Itagaki, H. J. Photopolym. Sci. Technol. 2011, 24(5), 517-521.

4. Khan, A.; Khan, R. A.; Salmieri, S.; Tien, C. L.; Riedl, B.; Bouchard, J.; Chauve, G.; Tan, V.; Kamal, M. R. Carbohydr. Polym. 2012, 90 , 8, 1601-1608.

5. Motawie, A.M.; Mahmoud, K. F.; El-Sawy, A.A.; Kamal, H. M.; Hefni, H.; Ibrahiem, H.A. Egypt. J. Petrol. 2014, 23, 221-228.

6. Tirtom, V.N.; Dincer, A.; Bacerik, A., Aydemir, T.; Celik, A. Chem. Eng. J. 2012, 197(8), 379386.

7. Suye, S. I.; Mizusawa, A. Se'i Gakkaishi 1999, 55(2), 73-77.
8. Laus, R.; Costa, T. G.; Szpoganicz, B.; Favere, V.T. J. Hazard. Mater, 2010, 183, 233-241.

9. Rahmi; Fathurrahmi; Irwansyah; Purnaratrie, A., Orient. J. Chem. 2015, 31(4), 20712076.

10. Rahmi, Asian J. Chem. 2016, 28(10), 22672271.

11. Hassan, S. B.; Aigbodion, V.S. J.King Saud University-Engineering Sci. 2015, 27, 4956.

12. Mohammadnezhad, J.; Soreshjani, F.K.; Bakshi, H. Desalination and Water Treatment, 2014, 1-12

13. Ni, M.; Ratner B.D. Surf. Interface Anal. 2008 , 1-19.

14. Paulino, A. T.; Santos, L. B.; Nozaki, J. React. Funct. Polym. 2008, 68, 634-642.

15. Wang, J.; Becker, U. American Mineralogist, 2009, 94, 380-386. 